\title{
Effects of Post-synthesis Thermal Conditions on Methylammonium Lead Halide Perovskite: Band Bending at Grain Boundaries and Its Impacts on Solar Cell Performance
}

Daehan Kim ${ }^{1}$, Gee Yeong Kim ${ }^{2}$, Changhyun $\mathrm{Ko}^{3}$, Seong Ryul Pae ${ }^{1}$, Yun Seog Lee ${ }^{4}$, Oki Gunawan $^{4}$, D. Frank Ogletree ${ }^{5,6}$, William Jo*2, Byungha Shin $*^{1}$

\footnotetext{
${ }^{1}$ Department of Materials Science and Engineering, Korea Advanced Institute of Science and Technology, Daejeon 34141, South Korea.

${ }^{2}$ Department of Physics, Ewha Womans University, Seoul 120-750, South Korea.

${ }^{3}$ Department of Materials Science and Engineering, University of California, Berkeley, CA 94720, USA.

${ }^{4}$ IBM T.J. Watson Research Center, Yorktown Heights, NY 10598, USA

${ }^{5}$ Molecular Foundry, Lawrence Berkeley National Laboratory, California 94720, USA.

${ }^{6}$ Materials Sciences Division, Lawrence Berkeley National Laboratory, California 94720, USA.

E-mail: byungha@kaist.ac.kr, wmjo@ewha.ac.kr
} 


\section{Experimental}

Solar cell fabrication. FTO (TEC 8) was washed using acetone, ethanol, and deionized water. And prepared compact $\mathrm{TiO}_{2}$ solution (TTIP precursor solution) was spin-coated on FTO with a rotation speed of $3000 \mathrm{rpm}$ for $30 \mathrm{sec}$, followed by annealing at $500^{\circ} \mathrm{C}$ for $30 \mathrm{~min}$. Paste diluted meso- $\mathrm{TiO}_{2}$ solution (paste purchased from Dyesol, ethanol base) was spin-coated on c- $\mathrm{TiO}_{2}$ with $4500 \mathrm{rpm}, 30 \mathrm{sec}$, followed by $500^{\circ} \mathrm{C} 30 \mathrm{~min}$. Prepared $\mathrm{PbI}_{2}$ precursor solution $\left(\mathrm{PbI}_{2}: \mathrm{DMF}=500 \mathrm{mg}: 1 \mathrm{ml}\right)$ was deposited using spin-coating $(6500 \mathrm{rpm}, 6.5 \mathrm{sec}, 30$ sec). At once, $200 \mu \mathrm{l}$ MAI precursor solution (MAI : iso-propanol $=30 \mathrm{mg}: 1 \mathrm{ml}$ ) is poured on the $\mathrm{PbI}_{2} / \mathrm{m}^{-}$ $\mathrm{TiO}_{2} / \mathrm{c}-\mathrm{TiO}_{2} / \mathrm{FTO}$ film, and holding $25 \mathrm{sec}$ for enough inter-diffusion. The film is spin-coated (6500 rpm, $6.5 \mathrm{sec}$, $30 \mathrm{sec}$ ), and then the film is annealed on hot plate for $10 \mathrm{~min}, 5$ hour in $100{ }^{\circ} \mathrm{C}$, respectively. Prepared doped spiro-OMeTAD solution (spiro-OMeTAD powder $72.3 \mathrm{mg}$, Li-TFSI (synthesized using $520 \mathrm{mg}$ in acetonitrile 1 ml) $17.5 \square$, 4-tert-Butylpyridine $28.8 \square$, chlorobenzene $1 \mathrm{ml}$ ) is deposited using spin-coating (3000 rpm, $3 \mathrm{sec}$, $30 \mathrm{sec})$. Lastly, Au electrode is deposited using a thermal evaporator about $80 \mathrm{~nm}$.

Characterization. Local electrical properties were characterized by KPFM and c-AFM measurements by an AFM (Nanofocus Inc., n-Tracer) with a Pt/Ir coated silicon cantilever (Nanosensor) under $\mathrm{N}_{2}$ atmosphere inside glove box. Topography and surface potential images were obtained at the non-contact mode with applying AC voltage with an amplitude of $1.0 \mathrm{~V}$. The frequency of $50 \mathrm{kHz}$ and the scan size of the images are $5 \times 5 \mathrm{~m}^{2}$. The scanning rate was $0.5 \mathrm{~Hz}$ to reduce the topological signal. The local current map images were obtained by cAFM with applying external bias of $1.0 \mathrm{~V}$ to the sample. The FTO layer was considered as a back contact and the metal-coated tip is top electrode. The activated AC amplitude is $5 \mathrm{~V}$ and frequency $60 \mathrm{kHz}$ using Pt/Ir coated Si cantilever. Solar simulator (McScience) and the QEXL Solar Cell Quantum Efficiency / IPCE / Spectral Response Measurement System (PV measurement) are used for device characteristics. Nano-Auger electron spectroscopy (Nano-AES) was performed employing an Oxford/Omicron Nano-Auger system equipped with an ultra-high vacuum chamber (base pressure low E-10 mbar), a field emission gun and a multi-channel hemisphere energy detector. The electron beam can be focused to less than $10 \mathrm{~nm}$ diameter, which enables the nanoscale chemical analysis. 

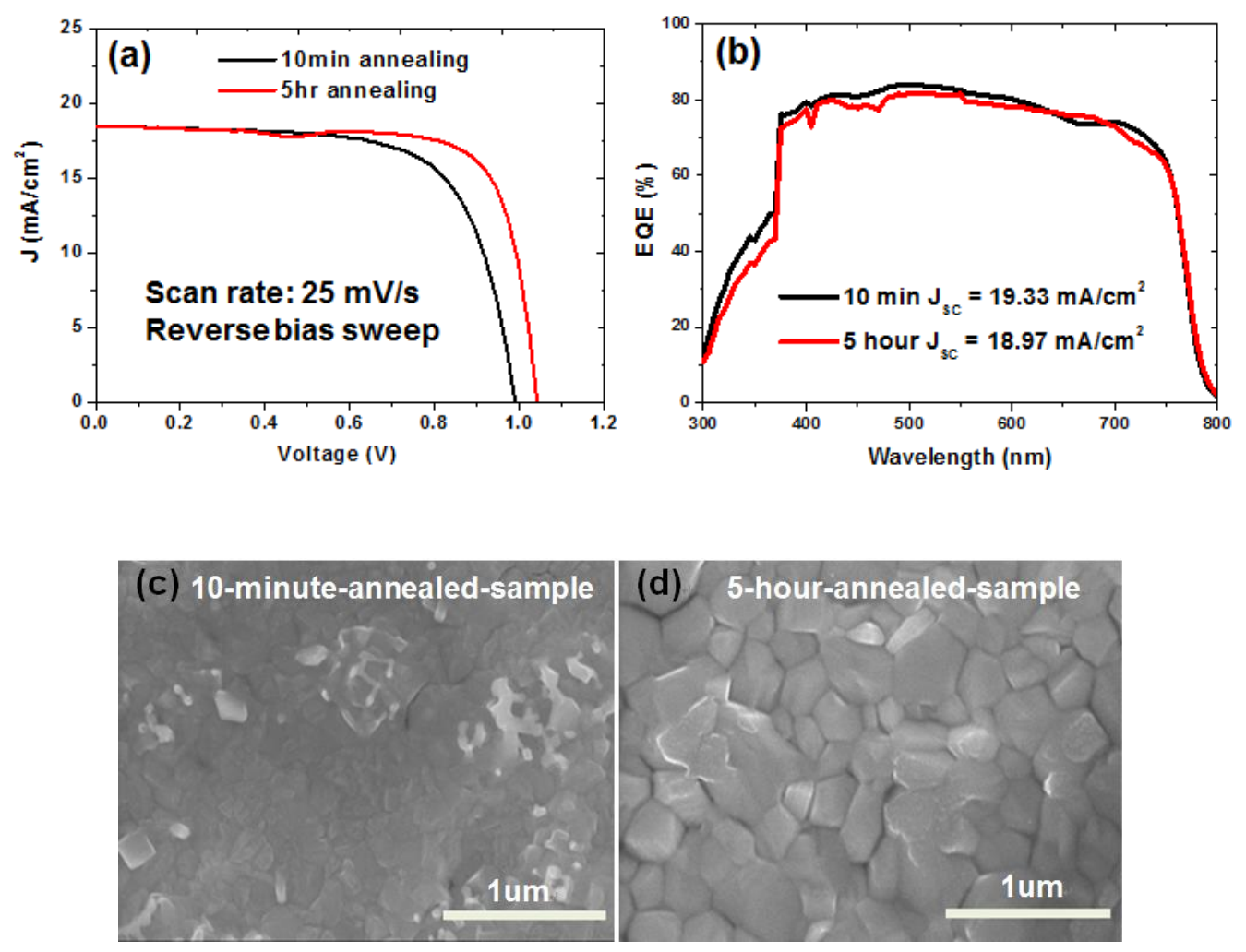

Figure S1. (a) Current density vs. voltage characteristics under a simulated 1-Sun (AM1.5G, 100mW/ $\mathrm{cm}^{2}$ ) illumination condition and (b) External quantum efficiency spectrum of perovskite solar cells with 10-minute (black) and 5-hour (red) annealing durations. SEM images of top surfaces of perovskite films with (c) 10-minute and (d) 5-hour annealing durations.

\begin{tabular}{|c|c|c|c|c|}
\hline Annealing duration & Efficiency (\%) & $V_{\mathrm{OC}}(\mathrm{V})$ & $J_{\mathrm{SC}}\left(\mathrm{mA} / \mathrm{cm}^{2}\right)$ & FF (\%) \\
\hline 10 minutes & 12.55 & 0.99 & 18.40 & 68.89 \\
\hline 5 hours & 14.58 & 1.042 & 18.44 & 75.88 \\
\hline
\end{tabular}

Table S1. Photovoltaic parameters of both 10-minute- and 5-hour-annealed perovskite devices 


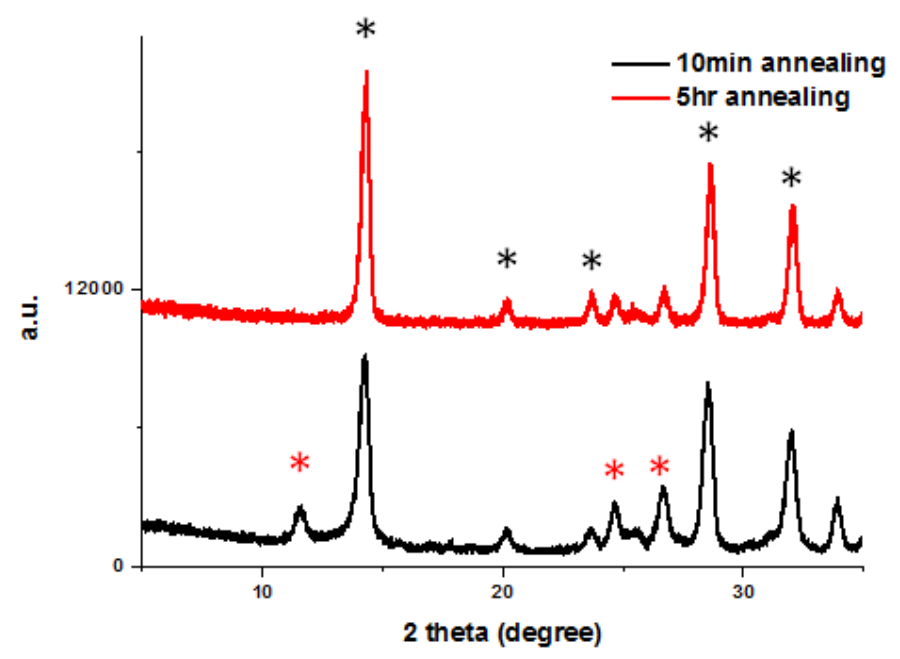

Fiugre S2. XRD pattern of perovskite film with different annealing time (* notation means perovskite peak indexing, * notation means lead iodide peak indexing

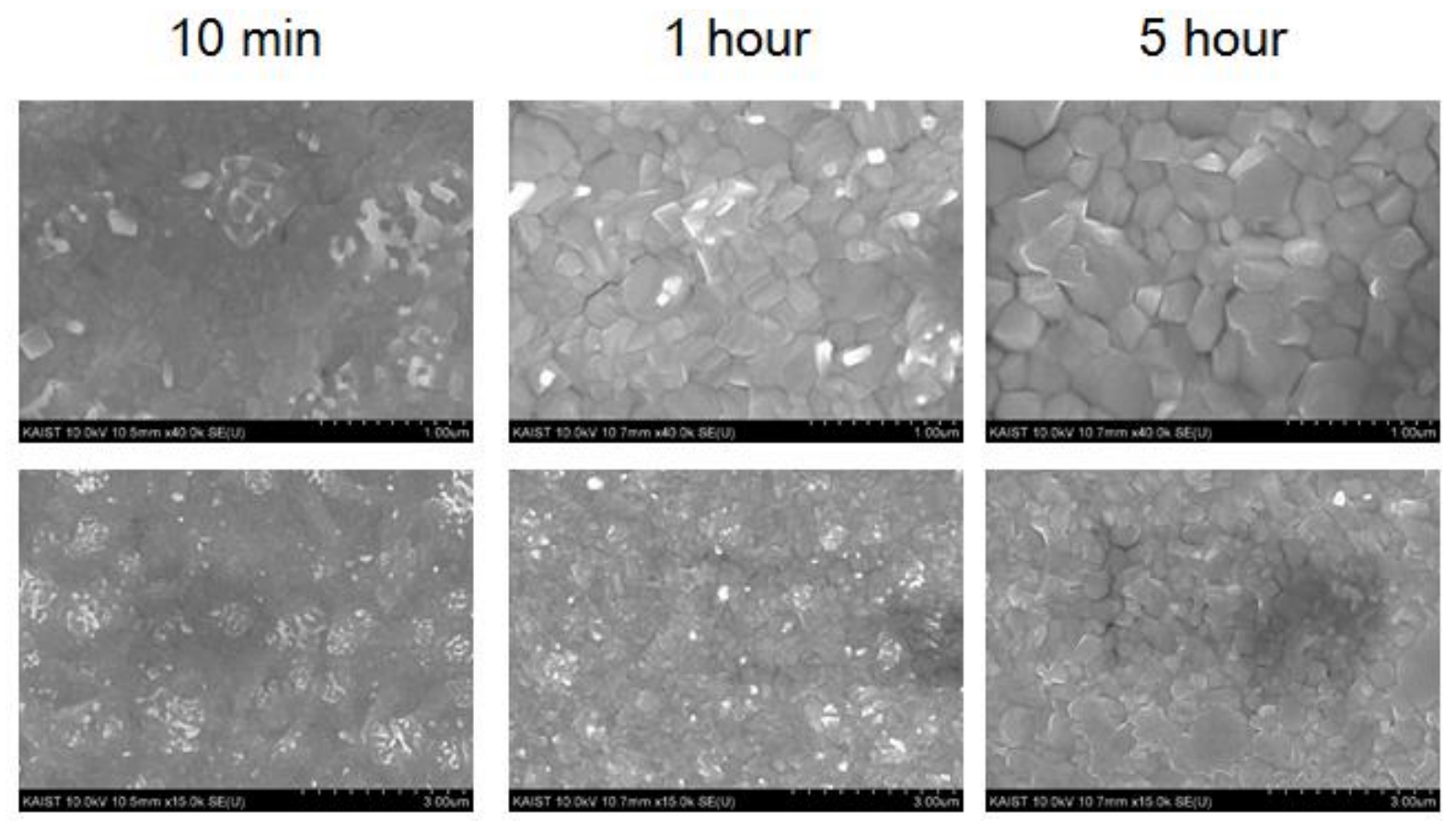

Figure S3. SEM images with different annealing time 

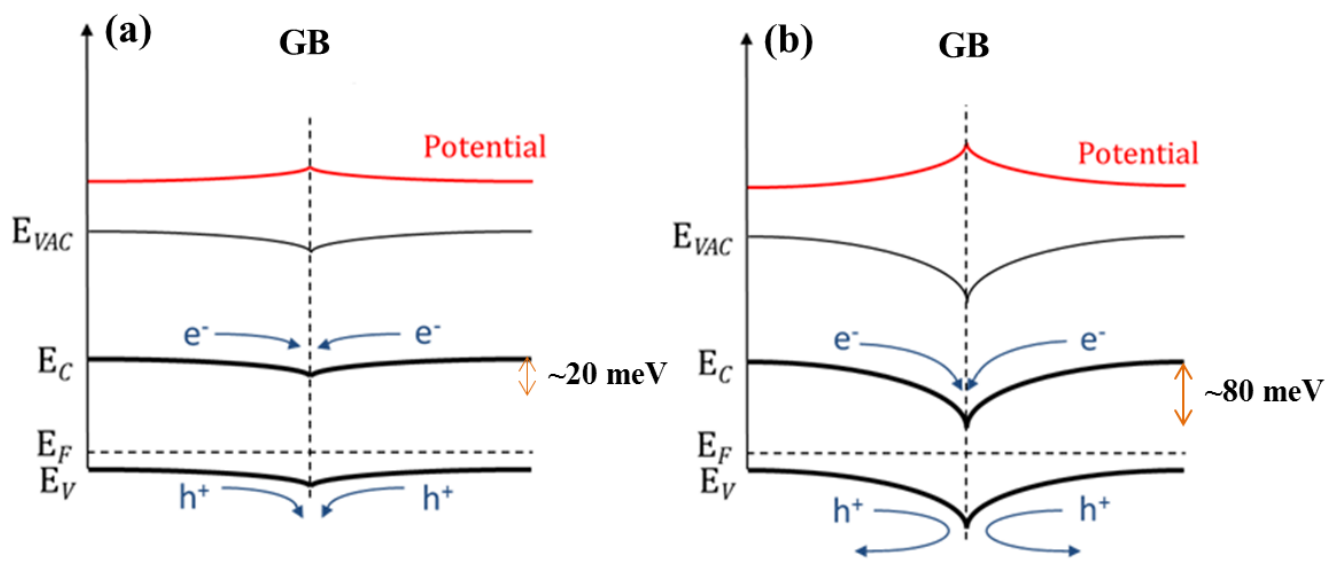

Figure S4. Schematic diagram of proposed energy band bending and charge carrier dynamics of (a) 10minuteannealed and (b) 5-hour-annealed samples
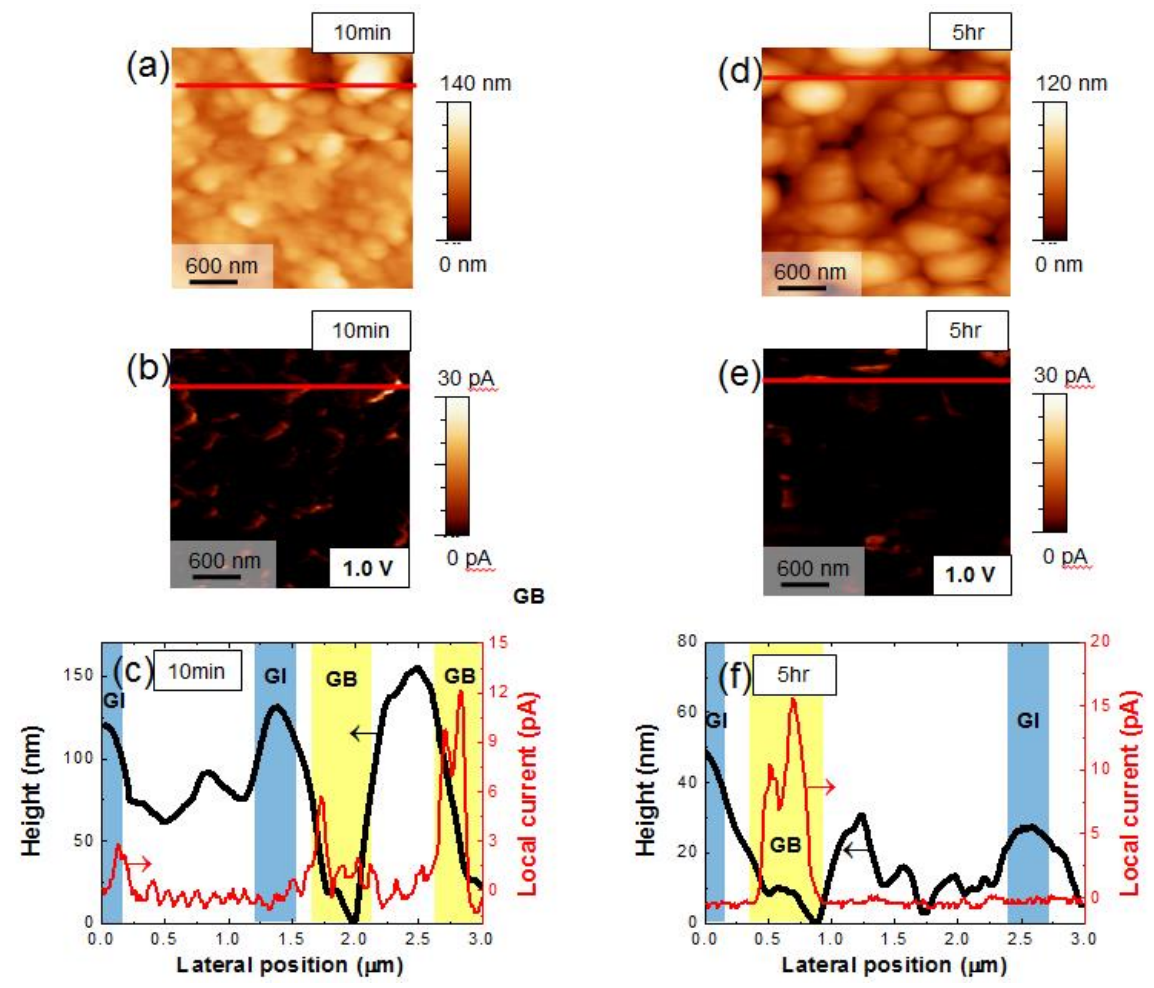

Figure S5. (a) and (d) AFM topography images, (b) and (e) local current mapping images from c-AFM, (c) and (f) morphology and current line profiles of the perovskite layer. The external bias $1 \mathrm{~V}$ is applied to the samples. High current up to $15 \mathrm{pA}$ flows through the GBs in the 5-hour-annealed-sample 
Nano auger spectroscopic results were acquired four different regions of grain boundary (GB) and grain interior (GI) for both 5-hour and 10-minute-annealed perovskite sample. Shown below is a table listing peak-topeak height of differentiated Auger spectra of $\mathrm{Pb}, \mathrm{N}$, and I along with ratios of $\mathrm{Pb}$ to I and $\mathrm{N}$ to $\mathrm{I}$.

\begin{tabular}{|c|c|c|c|c|c|c|c|c|c|c|c|c|}
\hline & & $\begin{array}{c}\mathrm{Pb} \\
\text { raw auger } \\
\text { intensity }\end{array}$ & $\begin{array}{c}\mathrm{N} \\
\text { raw auger } \\
\text { intensity }\end{array}$ & $\begin{array}{c}\mathrm{I} \\
\text { raw auger } \\
\text { intensity }\end{array}$ & $\begin{array}{l}\mathrm{Pb} / \mathrm{I} \\
\text { ratio }\end{array}$ & $\begin{array}{l}\mathrm{N} / \mathrm{I} \\
\text { ratio }\end{array}$ & & $\begin{array}{c}\mathrm{Pb} \\
\text { raw auger } \\
\text { intensity }\end{array}$ & $\begin{array}{c}\mathrm{N} \\
\text { raw auger } \\
\text { intensity } \\
\end{array}$ & $\begin{array}{c}\mathrm{I} \\
\text { raw auger } \\
\text { intensity }\end{array}$ & $\begin{array}{l}\mathrm{Pb} / \mathrm{I} \\
\text { ratio }\end{array}$ & $\begin{array}{c}\mathrm{N} / \mathrm{I} \\
\text { ratio }\end{array}$ \\
\hline \multirow{6}{*}{$5 \mathrm{hr}$} & GB01 & 27812.72 & 27534.13 & 92678.47 & 0.300 & 0.297 & GI01 & 30687.93 & 22955.06 & 87458.76 & 0.350 & 0.262 \\
\hline & GB02 & 29229.15 & 25687.2 & 91141.91 & 0.320 & 0.281 & GI02 & 34095.69 & 20910.73 & 89290.03 & 0.381 & 0.234 \\
\hline & GB03 & 28358.53 & 27552.24 & 92747.13 & 0.305 & 0.297 & GI03 & 32553.24 & 24177.35 & 91242.1 & 0.356 & 0.264 \\
\hline & GB04 & 32690.02 & 22827.07 & 89448.2 & 0.365 & 0.255 & GI04 & 32914.77 & 21168.84 & 88624.94 & 0.371 & 0.238 \\
\hline & $\begin{array}{l}\text { Avera } \\
\text { ge }\end{array}$ & 29522.61 & 25900.16 & 91503.93 & 0.322 & 0.283 & $\begin{array}{l}\text { Avera } \\
\text { ge }\end{array}$ & 32562.91 & 22302.99 & 89153.96 & 0.365 & 0.250 \\
\hline & $\begin{array}{c}\text { STDE } \\
\mathrm{V}\end{array}$ & 2190.69 & 2227.739 & 1558.008 & 0.029 & 0.019 & $\begin{array}{c}\text { STDE } \\
\mathrm{V}\end{array}$ & 1412.902 & 1545.221 & 1584.555 & 0.014 & 0.015 \\
\hline \multirow{6}{*}{$\begin{array}{c}10 \\
\text { min }\end{array}$} & GB01 & 34483.9 & 9969.626 & 81829.06 & 0.421 & 0.121 & GI01 & 36669.7 & 6247.979 & 82197.22 & 0.446 & 0.076 \\
\hline & GB02 & 31793.47 & 13870.67 & 81563.86 & 0.389 & 0.170 & GI02 & 32439.8 & 6055.971 & 74161.29 & 0.437 & 0.081 \\
\hline & GB03 & 26631.03 & 12064.85 & 72691.31 & 0.366 & 0.165 & GI03 & 34637.52 & 7312.458 & 76662.31 & 0.451 & 0.095 \\
\hline & GB04 & 38327.6 & 12972.87 & 85617.69 & 0.447 & 0.151 & GI04 & 32857.32 & 5902.357 & 72634.96 & 0.452 & 0.081 \\
\hline & $\begin{array}{l}\text { Avera } \\
\text { ge }\end{array}$ & 32809 & 12219.51 & 80425.48 & 0.407 & 0.151 & $\begin{array}{l}\text { Avera } \\
\text { ge }\end{array}$ & 34151.09 & 6379.691 & 76413.95 & 0.446 & 0.083 \\
\hline & $\begin{array}{c}\text { STDE } \\
\text { V }\end{array}$ & 4914.563 & 1671.307 & 5478.518 & 0.035 & 0.022 & $\begin{array}{c}\text { STDE } \\
\text { V }\end{array}$ & 1930.66 & 637.7159 & 4197.743 & 0.006 & 0.008 \\
\hline
\end{tabular}

Table S2. Table of statistics of raw Nano-AES data taken eight different GB and GI regions from each sample.
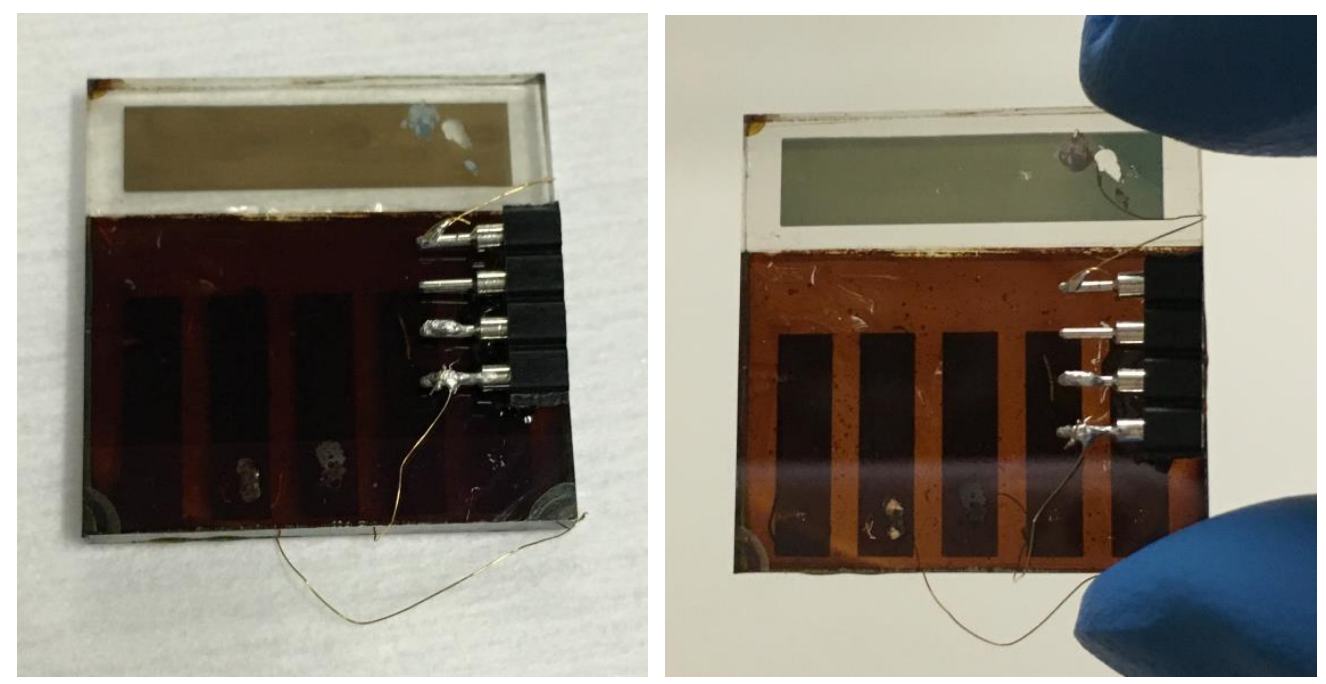

Figure S6. Perovskite device samples after temperature-dependent light $J$ - $V$ measurement 
(a)
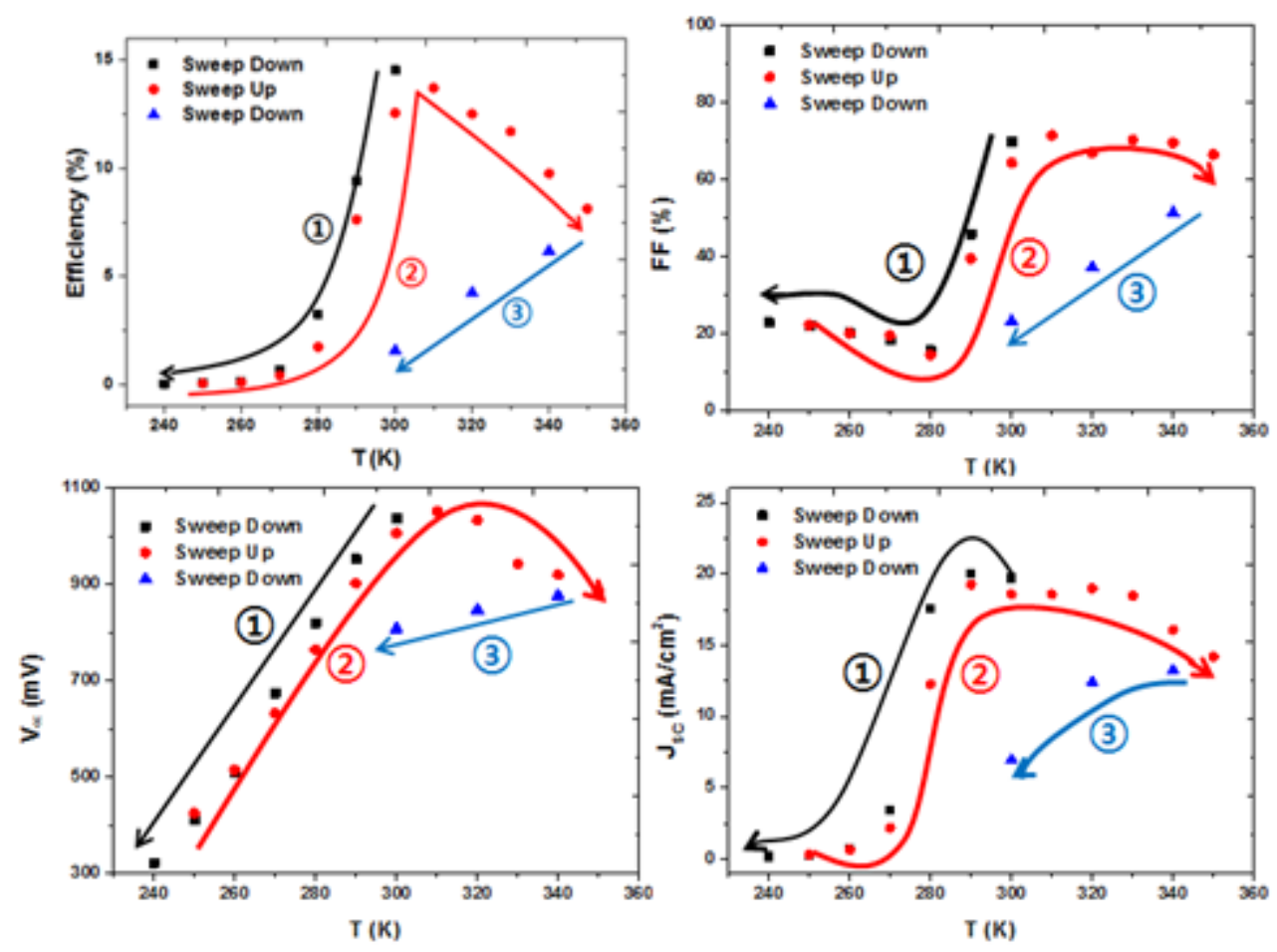

(b)
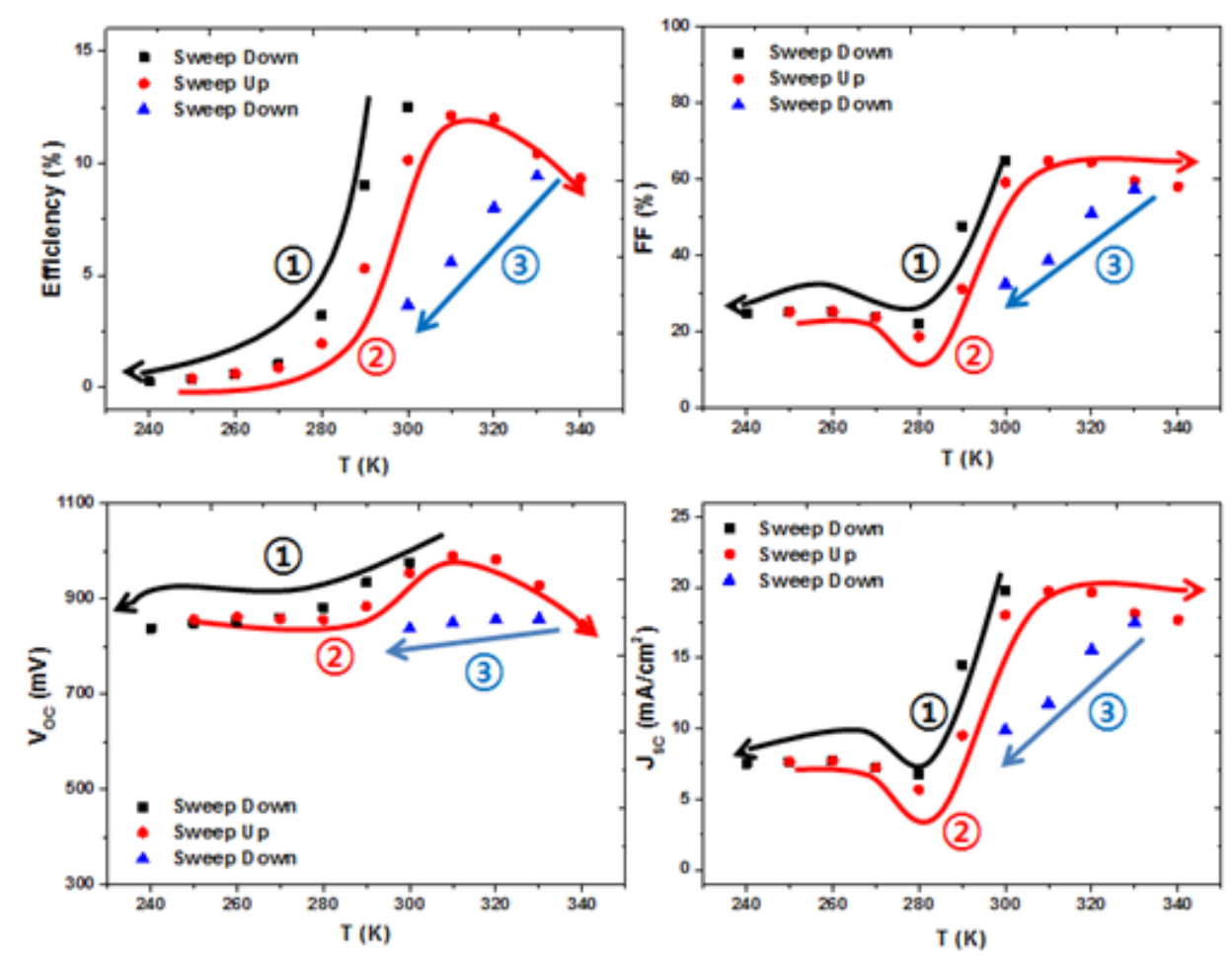

Figure S7. Photovoltaic parameters vs. temperature plots for 5 hour-annealed-sample (a), 10 minute-annealedsample (b) 